IASSIST Newsletter, Vol. 3, No. 1 (Winter 1979)

\title{
PEACE RESEARCH AND INFORMATION SYSTEMS
}

Carl Beck

University of Pittsburgh

In a recent article I wrote that "the need for information retrieval systems in the social sciences is both real and apparent, but given the ability of many researchers to gather idiosyncratic research support, the need is not perceived as acute. The evidence that is not perceived as acute is that few scholars are willing to amend their usual behaviors to participate in the building of an effective information base which could be shared by social scientists. With the seeming inability of anyone to stem the information explosion and with few positive steps having been taken recently to improve access, the information environment in which we operate has continued to deteriorate. Unfortunately, that deterioration is still not perceived by most researchers as acute, and the literature is still concerned more with technology and conceptualization than on results.

The impact of a less than a cequate information environment is particularly felt by those engaged in a multi-disciplinary study such as peace research. In peace research there are no established authorities and no established and formalized schools of thought, therefore, the peace researcher must engage in a widely ranging information search behavior in order to touch all of the relevant information bases. Peace researchers are also challenged by being in a field which is policy related. Peace research is by its very nature bound to intrude upon national sensitivities, ideological sensitivities, and/or academic sensitivities. If peace researchers are to go beyond the merely polemi- cal in a way that will be attended to by academic and policy colleagues they must be able to document their position effectively. Their ability to be effective is going to depend upon their ability to manipulate a basically uncontrollable information environment. Effective access to information is required if theory buffeted about by information is to be the basis for conclusions reached as a result of peace research.

Unfortunately, we live in an unstructured information environment particularly in the social sciences. It seems beyond anyone's control, even UNESCO's. We are dependent upon information structure to organize and facilitate access to that information environment. Yet every existing information structure provides only partial access for a number of reasons that I will discuss later. There have been some important contributions; the work of Alan Newcomb; the work of the International Political Science Association and the work of my own University Center for International studies in the development of the United States Political Science Information Service are examples. If this report stresses the characteristics of United States Political Science Information Service it is only because I am better acquainted with the ins and outs of that service. But, I believe, that even those who have participated in these activities would recognize the partial nature of their contribution. As more data are collected and discussed the information environment 
IASSIST Newsletter, Vol. 3, No. I (winter 1979)

expands and the ability of an individual researcher to control that environment contracts. Partial access to information has many debilitating consequences.

It leads to waste of research resources; it strengthens academic imperialism and orthodoxy; it reinforces tendencies toward the reification of authorities; it even reinforces global divisions such as the North-South division. It also makes it very difficult for new fields of inquirty to develop, or to sustain themselves. I believe that the problem of information access is endemic in the social sciences and particularly acute for persons engaged in peace research.

The remarks in this paper are focused on problems and possibilities for the integration of documentation and information relevant for peace and conflict studies into social sciences information systems and for the use of such systems by peace researchers. There is an additional emphasis upon the delivery of such information to individuals in developing nations, although I tend to believe that the problem confronting scholars in any field that is multi-disciplinary, social scientific and policy related is probably no greater in developing nations than the same problem is in most developed nations -- in fact, it may even be easier at least to initiate fields of inquiry in those nations in that existing educational institutional structures are less formalized.

Much of what I have suggested stems from three positive experiences and from one very strong frustration stemming from other experiences. The positive sets of experience are those associated with the development of the United States Political Science Information System, those associated with my role as Executive Director of the International Studies Association, one of whose thematic sections is a Peace Studies Section; and those associated with my role as Director of the University Center for International studies, a multi-disciplinary center concerned with internationalizing the teaching, research and service facilities and programs at the University of Pittsburgh. There exists in these cases a symbiotic relationship between information systems and substantive research. We have found that the more effort we put into developing interactive information systems the more effort we will able to devote to the analytical characteristics of research rathern than the bibliographic. In doing so we learned a great dela about the conceptual, technical, and organizational problems confronting the development of an information system and the dissemination of information from one such center to another.

The frustrations stem from a decade of committee work in such ill fated activities as the Information Retrieval Committee of the Council of Social Science Data Archives, and other international and national committee's whose efforts here produced many reports, workshop statements, guidelines, but whose contributions to anything operative that improves structured access to information has been very I imited. These experiences have reinforced a very strong prejudice which you will see running throughout this paper: to concentrate only on THE Thesaurus, THE information program, THE information retrieval system, and to believe at the same time that this constitutes a direct and positive contribution to improving information access is to engage in an illusionn. The illusion is satisfying and, indeed. the development of improved concep- 
tualizations

important and will shape the future, but we can't risk the present for the future. Since this type of prejudice has, in the past, been described often as American pragmatism I might as well plead guilty to it. However, just for the record it should no longer be considered as American pragmaticism as American research support agencies such as the National Science Foundation, the office of Education, the Ford Foundation, etc., have made it abundantly clear that they believe the opeational dimensions of system design and development to be beneath them. Someone has been very successful in presuading them that the "American" concern with getting a system running is not as respectable as the European concern with informatics. I believe we need both; we can deliver the something that works and that meets information needs with very little effort and very little funding. Indeed, I think one could easily document that any investment in information systems would soon be recouped. The often discussed formula is that $25 \%$ of a research budget goes into bibliographic searching. My guess is that 258 is too low (Committee on Scientific Technical Information, $1970,1976 a, 1976 b$ )

In a discussion of how to get relevant information into information systems appropriate for peace research we have to begin with some truisms. I will not dwell on the truisms of what constitutes an effective information system. We all know that an information system to be useful and to be used must meet the needs of its users. In the conceptualization and design of an information service the nature of the inforamtion to be made available and the nature of the information behaviors of the users to be served must be analyzed or if that is not possible at least inferred from known information structures and known behaviors with space left in the conceptualization and design for unknowns. Therefore, we have to start with the question of what constitutes peach research. David singer suggests there are three major streams to peace research: (1) the pure science school who justify their research on grounds of intellectual curiosity; (2) the applied science school that believe that their research will end human suffering; and (3) the radical critique school. Singer suggests that three major substantive issues shape the field: strategic deterrence, social reform, and economic development (Singer, 1976).

What are some of the major concepts that mark peace research? If we approach this question by building a narrow profile of peace research and then see what types of terms and concepts as that profile is used to search the United States Political Science Documents, International Political Science Abstracts and Psychological Abstracts, we get a view of some of the major terms.

1. Agreements, including such items as alliances, contracts, blocs, fronts, state agreements, private agreements, international organizations;

2. Conflict, including such items as aggression, agitation, economic conElict, ideological conflict, social conflict, wa $r$;

3. Crisis including conflict management, such items as management, 
IASSIST Newsletter, Vol. 3, No. 1 (Winter 1979)

diplomacy, strategy, bargaining, peace keeping, arms control;

4. Weaponary, including such items as arms, missles, military characteristics;

5. Structures, including structural prerequisites for world order, peace keeping forces, international law;

6. Peace science, including the search for behavioral and structural predictors of peace, correlates of war, events and even analysis;

7. Psychologyical conditions, ranging from aggression to consciousness (International Peace Research Newsletter, $7(3))$; and

8. Special methodologies, such as fights, games, simulations.

And of course with all of these the array of methodologies, concepts and analytical modes that can be used to discuss them.

Peace researchers as a group will want to be able to search a very wide body of literature, certainly encompassing all of the social sciences and social psychology as well. If we add to that some peace researchers concern with concepts such as consciousness, extracts from the literature of clinical psychology and psychotherapy will probably also be relevant. Additionally researchers will also be concerned with direct policy impacts and they will want to be able to monitor events and specialized transactions as well.
The information environment that is characterized by the aggregated information needs of peace researchers is therefore immense. I believe the size of this environment constitutes the single most difficult problem in developing peace research information systems or in getting peace research information into operating information systems so that peace researchers will use such systems. Before discussing sources as a major item of this paper let us discuss in more traditional fashion some of the parameters of the development of a peace research information system.

\section{Terminological control.} Information systems vary in the way in whch they search textual information from full text searching to some system of terminological control in which both indexers and users are acquainted with a codebook of terms. Weak information systems rest upon a set of descriptors; strong information systems have a structured thesaurus. With testing and refinement the Political Science Thesaurus will meet all of the terminological requirements of peace research information systems in English. Such testing is now underway at the University Center for International studies. A revised thesaurus, along with appropriate changes in the computer files, will be available sometime in 1980 .

The limitation is that this Thesaurus is only in English and our conceptu- 
alizations of language and 1 inguistic structure are not developed enough to allow for direct translation from a Thesaurus in one language to another. However, even with the sloppiness that will be built into direct translation we ought to be experimenting with it by running a translated Thesaurus against existing information data bases. The fact that most computer readable information services are in English, and even more limiting, drawn from English language sources, limits the possibility of building peace research from many different perspectives and traditions (Sartori, et al., 1975).

2. Levels of Information. The design of an information system or the design of a format for machine readable descriptions of textual information always involves tradeoffs. I believe that one area that we cannot allow to be weak and partial is in the number of levels of information that should be included. These include a document number, author, contributors, title, source, abstract, tables, Eigures and charts, cited authors, subject descriptor (developed from the Thesaurus), geographic descriptors (developed from the Thesaurus), and significant proper names.

I wish that we had added one more, headings in the article, and I wish that we had included the title of the citation as well as the author. However, since we have been operating on no funds except the subsidy that the university of Pittsburgh is providing to cover our deficit, it is perhaps astonishing that we have come as far as we have. We made the strong levels of information decision in the belief that by so doing no one would ever have to go back to these documentary representations of scholarly articles to add information, no matter who the clients might be for the information service. I believe we were right. We were also right in not allowing authors to write their own abstracts. Our experience shows that authors tend to abstract the article they wish they had written rather than the article they wrote.

3. Information Retrieval System. Since the computer became a tool of social research, millions of hours have been spent discussing and designing information retrieval systems in the hope that THE system could be established. I used the term "strong" to describe at least one systems approach to the levels of information problem in information systems. I would use the term "strong" in regards to information retrieval systems when those sys- 
tems are easily understood, easily manipulated and fully flexible. Its internal nature should be left to those who have to mesh hardware and software requirements. RECON is still an excellent model. So are DIALOG (Lockheed), ORBIT (SDC), STAIRS (BRS), WISE (a New York Consortium), TRIAL (Northwestern University), AND PIRETS (University of Pittsburgh). The design of such systems and changing of the necessary programs is now a matter of routine. The swapping of data and information bases is much more important a process in getting information to be used than is the swapping of programs. We have run USPSD tapes on DIALOG, on ORBIT, on TRIAL, and on PIRETS, and on homegrown programs for small IBM computers, large CDC computers, etc. We are always glad to discuss with any institute interested in swapping information bases, mutual participation in the design and implementatin of a retrieval system for access to the swapped materials.

4. Dissemination. What do we know about the format requirements of users of a computer-readable information system? Actually, we do not know very much. We feel that users do not like to read computer output. I know I do not. We feel that some scholars want tradi- tionally structured information and that other scholars want information sources that they can manipulate. A strong information system will then produce multiple products. A weak one will produce its product in only one or two formats. In USPSIS we produce the following: an annual publication of the entire contents of the yearly file; a set of derivative publications in which certain documents which clusters around a theme are pulled from the file and printed on an annual basis (Ethnic Studies, Strategic Studies, Intercultural Studies, Russian and East European Studies, Asian Studies, and if we could expand our sources - - see below -- peace research); individualized searches in which clients may write or call and discuss their information needs from which we will generate a custom designed profile and run it against all of our holdings (currently about 600,000 entries); tape leasing in which an institute may lease the tapes receiving a new one each quarter; tape leasing to commercial systems which we do through both Lockheed and SDC, and soon may be even microfiche and microfilm. All of these outputs seem easy to generate. What is not easy is to know which will please clients. 
5. Sources. Here is the weakness of all existing answers to the question of how can we help peace researchers meet their information needs. Even the literature of the United states, which is the best covered, is badly covered. We can demonstrate this by asking what sets of sources are potentially of interest of peace researchers and how much of a particular set can they access on a sustained basis. Please note that I have raised the question, not in terms of articles in specific journals or specific occasional paper series because I believe it is wasteful and inefficient in terms of financing and in terms of meeting the needs of the diverse clientele which constitute peace research to select journals for inclusion in a peace research system. The computer should do the selection: one person's peace and conflict studies literature may not be another's. In the interest of helping researchers we should be able to tell them what materials are covered by an information system. If article are the level of inclusion in a system the client will never really know whether or not a journal has been fully covered by his or her search. When a decision is made to include a journal in a system all articles in that journal should be included so that a user of the system does not have a fret about full coverage and so that later another abstractor/indexer does not have to go back and fill in holes. Also data/information files can be more easily swapped than networks created. It should be noted that I am using a low level concept such as swapping rather than a higher level concept such as networking because I believe that swapping is possible now and that networking requires both organizational and technological development to be efficient. It doesn't require much but swapping, as I discussed it in the conclusion of this paper, can be done today.

a) Journals: It is a safe statement that through Sociological Abstracts, Psychological Abstracts, United States Political Science Documents, the journal literature published in the U.S. relevant to peace research is handled and handled well. Clients who wish to search this literature can do so in published format, machine manipulable format, and in some cases tapes can be purchased or exchanged. Through the work of Alan Newcomb and International Political Science Abstracts some of the international literature can also be searched. The English abstracts of 
International Political Science Abstracts can be searched by computer through the United States Political Science Information Service. The most effective organizational arrangement for improving the coverage of journal literature is by the development of national or regional equivalents to the work of any of the above. Certainly, this is the stated goal of at least one of the above information services and discussions are now under way with a number of institutions on how to bring this objective to fruition.

b) Books. It is a fair statement that no existing service adequately handles access to books for peace researchers. In the future when the Journal of Economic Literature goes into a computer based information system some progress will have been made. A major issue with this is how to describe the contents of a book adequately to help the client determine whether a study is relevant to the client's needs. Those of us who believe in strong information services argue that books should be analyzed on a chapter basis in as structured a format as journal articles. Unfortunately, at this moment no one provides the resources even to do the experimentation necessary to determine whether the cost is worth the effort. Experiments on how to describe books for the purpose of inclusion in machine readable information systems are critically important. Perhaps the Journal of Economic Literatur ${ }^{\prime}$ 's approach of a critical descriptive review is adequate. One service will be exploring soon the possibility of some subvention from book publishers for inclusion of their products in the service.

c) Convention papers. Given the expansive nature of peace research interests, the lack of definition of the field, and given the wide range of authorities -- particularly of informational authorities -the life of information in peace research is very short. Much of the information exists in ephemera or in fugitive files. Three major examples of this type of information are convention papers, peace research conference proceedings, and occasional or working papers. ERIC is about the only 
system that handles convention papers and even there it does not do it particularly well. Most associations no longer even list convention papers. The only one that I know that does so on a continuous basis and makes them available for purchase after the convention is the International Studies Association. Yet convention papers are not hard to organize. Often they $\mathrm{c}$ an be grouped around a panel which makes the collection of such papers relatively easy. A hopeful sign is the work being done at the Carleton School of International Affairs under the leadership of Jane Baumont. She is collecting the titles of convention papers. computerizing them and doing searches using Key World in Context (KWIC) procedures. It is at least a start.

d) Conference proceedings. In Vol XVII, No. 3 of the International Peace Research Newsletter, fifteen conferences important to peace research are listed. This seems rather typical. However, it will be interesting to see how many of the conference papers ever become part of the information environment which we can access. These materials, I believe, are of particular interest to a peace researcher because of the nature of the field as discussed above.

e) Occasional papers and working papers. At times some of us have argued that publication is a symbolic act. By the time an article is published it may be known throughout the invisible college network by those who have their antenna out regarding the work of the author. A media of information that is important to the peace researcher is working papers of institutions. Many institutes have working paper series. John Fletcher has shown what can be done in regards to letting the world know about Economic Working Papers. This fall, Economic Working Papers will begin computerization and may be available through commercial information systems. Unfortunately, Economic Working Papers contains neither abstracts nor a structured terminological control system but $\mathrm{Mr}$. Fletcher is building a terminological control system inductively. His efforts deserve support.

f) Research Directory including research in 
IASSIST Newsletter, Vol. 3, No. 1 (Winter 1979)

TECHNOLOGICAL FORECASTING AND SOCIAL SCIENCE INFORMATION SERVICES

As ever greater demands are
placed on various resources, government, industry, and education around the world are attempting to better understand future technological developments so that better and more coherent planning can take place. As with other elements of technological societies, those people engaged in the delivery of information services must have some idea of the future in order to meet demands placed upon them by the end user. One of the problems with the delivery of such services is that we meet both technological and conceptual problems.

The technological problems are bound up in developments of computer and communicatins devices, whiole the conceptual problems relate to the issue of what data shall be saved and archived. Although the need for forecasting is evident, the techniques for proceeding with such forecasts is not at all apparent. One of the primary methods used to forecast and assess developments in technology is the Delphi Method. Delphi is useful under conditions where hard trend-line data are not available or where typical trend models are thought to lack descriptive power for future developments.

In order to assess future needs and problems concerning the delivery of machine readable information, with this issue we are beginning a Delphi study of the future developments in information technology and service. The first questionnaire appears in the current issue of the IASSIST Newsletter while a second questionnaire will appear in the Summer issue. A report of the findings will be presented in the Fall issue.

The Delphi Method is designed to elicit from a group of experts - in this case members of IASSIST -informed opinions regarding the future. It does this by first seeking from the experts suggestions about what developments (problems, events, techniques, equipment) will develop. The time frame you should consider is the period from 1980 through 2000. The first questionnaire to be presented is, therefore, essentially a blank sheet of paper.

Using all the imagination and information at your disposal we would like you to make some suggestions about what events and/or problems you believe will confront the delivery of information services over the next twenty years. From these open-ended responses will be developed a set of items which will be presented in the second questionnaire -- you will then be asked to rate each of the items in terms of the 1 ikelihood that an event will take place, an estimated date by which the event will take place, and the desirability that the event take place. From the set of responses to the second questionnaire an analysis will be developed which will present the findings of the study. 
IASSIST Newsletter, Vol. 3, No. 1 (winter 1979)

We are embarking on this study in an effort to further involve the members of IASSIST in developing goals and objectives for the future of information services and technology. In this insert space is provided for your responses. When you have completed as much of the questionnaire as possible, please return it to:

Thomas Wm. Madron

Academic Computing and Research

Services

Western Kentucky University

Bowl ing Green, KY 42101 USA

If you live outside the United States, please return the question- naire by Air Mail.

\section{PLEASE NOTE}

In order to prepare the second questionnaire we need as much time as possible. It is imperative that you complete and return your questionnaire as quickly as possible. We will structure the second questionnaire using those responses received by May 15, 1979. Your help and cooperation will be greatly appreciated. This is an opportunity to provide all of us with some information which should be useful in planning at our home institutionas as well as for IASSIST. Thanks.

WITH RESPECT TO EACH CATEGORY NOTED BELOW, PLEASE ANSWER THE FOLLOWING QUESTION: "What conditions will be facing those of us who deliver information services in the 1980 s and 1990 s?" Provide as many responses as you believe desirable in the form of short, declarative sentences.

PROBLEMS FOR INFORMATION SERVICES :

1.

2.

3.

4.

USER DEMANDS ON INFORMATION SERVICES: 
IASSIST Newsletter, Vol. 3, No. 1 (Winter 1979)

1.

2 .

3.

4.

NEW TECHNIQUES FOR DELIVERING INFORMATION SERVICES

1.

2.

3.

4.

EQUIPMENT NEEDS AND OPPORTUNITIES:

1. 
IASSIST Newsletter, Vol. 3, No. 1 (Winter 1979)

2 .

3.

4.

OTHER EVENTS OR CONDITIONS:

1.

2.

3.

4.

THANK YOU FOR YOUR PARTICIPATION

INSERT - 4 
IASSIST Newsletter, Tol. 3, No. 1 (Winter 1979)

progress. Peace

researchers need to know who is doing what in the field and what research is being undertaken. Directories of research in progress and biographical directories are important information bases for peace researchers. Newsletters such as International Peace Research contains invaluable information on who is doing what and what institutes are producing. But a more systematic and more easily updated system is required.

g) Policy Documents. Aside from the New York Times Information Bank what is there? Yet peace researchers need to know about transactions, ublic affairs, pronouncements by individual political actors. A model for this type of policy related information system in SCORPIO at the U.S. Library of Congress, but SCORPIO is not public and until it is it is of little use to peace researchers.

h) Specific Data Sets. In Vol. XVII. No. 3 of the International Peace Newsletter it is suggested that peace researchers should pay attention to such critical matters as food production. Yet how do we find data that we can manipulate for analytic purposes on food production? What is needed is an information system on data files available for secondary analysis. The characteristics of such a system are discussed by Paul E. Peters in SIGSOC Bulletin, Vol 6, No. 2-3, in 1974. Experimental work on developing such files was done by the University Center for International Studies as early as 1970. However, despite many international conferences on this subject, there is no service available.

6. Swapping and Networking . The information environment of the peace researcher is immense and continuously growing probably at an expanding rate. The structure for accessing the environment in a continuous controlled manner are inadequate. What can be done to improve this situation? There is always room for improvement in both the technology and terminology dimensions of an information service, but the major impediment is neither conceptual nor technical, it is organizational. We have had our sights set on THE system rather than on facilitating system interchange. If through inter-institutional

agreements research institutes would sector out the information environment and take on res- 
ponsibility for building machine-readable files of a sector with agreed upon standards on delivery time, on levels of information, and on terminological control, and then on conditions for swapping, swapping of files could become routine rather than the unusual. USPSIS would be glad, as I am sure many research institutes or services would be glad, to swap files, UNESCO could be of great assistance by providing seed money and organizational backing for such swaps. This many modal model would come closer to satisfying the needs of peace researchers than any one publication, or any one tape, or any one service. As the swaps became networks an infra-structure for peace researchers would develop, and perhaps even a demonstration model for international collaboration could emerge.

\section{REFERENCES}

Committee on Scientific Technical Information (1970). "Director of Federally Supported Information Analysis Centers." COSATI-70-1. PB 189300 . Springfield, VA: National Technical Information Services.

----- (1976a). "Progress of the United States Government in Scientific and Technical Communications." $\quad$ PB $\quad 180 \quad 867$. Springfield, VA: National Technical Information Services.

---- (1976b). "Proceedings of the Forum on Federally Supported information Analysis Centers." November 7-8, 1976. Sponsored by COSATI Panel 6. PB 177051. Springfield, VA: National Technical Information Services.

Sartori, Giovanni, Riggs, Fred W., and Teune, Henry. Tower of Babel: On the Definition and Analysis of Concepts in the Social Sciences. International Studies Association, Pittsburgh, 1975.

Singer, J. David. "An Assessment of Peace Research." International security. $1(1) \overline{\text {, Summer }}$ $\overline{1976,} 1 \overline{18-37}$. 